CORRECTION

https://doi.org/10.1038/s41586-018-0831-6

\title{
Author Correction: Emerging trends in global freshwater availability
}

M. Rodell, J. S. Famiglietti, D. N. Wiese, J. T. Reager,

H. K. Beaudoing, F. W. Landerer \& M.-H. Lo

Correction to: Nature https://doi.org/10.1038/s41586-018-0123-1, published online 16 May 2018.

In Fig. 2 of this Analysis, the tick-mark labels on the colour bars in the second and third images from the top were inadvertently swapped. In addition, the citation at the end of the sentence, "On a monthly basis GRACE can resolve TWS changes with sufficient accuracy over scales that range from approximately $200,000 \mathrm{~km}^{2}$ at low latitudes to about $90,000 \mathrm{~km}^{2}$ near the poles" should be to ref. ${ }^{4}$ not ref. ${ }^{1}$. These errors have been corrected online. 